ECONOMICS

\title{
US SHARE PRICES AND REAL SUPPLY AND DEMAND SHOCKS
}

by

Patricia Fraser

University of Aberdeen Business School

and

Nicolaas Groenewold

The University of Western Australia 


\title{
US SHARE PRICES AND REAL SUPPLY AND DEMAND SHOCKS
}

\author{
by
}

\author{
Patricia Fraser \\ University of Aberdeen Business School \\ Department of Accountancy and Finance, \\ Edward Wright Building, Dunbar Street, \\ Aberdeen AB24 3QY \\ Scotland, UK \\ Phone: +44 (0) 1224272210 \\ Fax: +44 (0) 1224272214 \\ E-mail: prof.p.fraser@abdn.ac.uk \\ and \\ Nicolaas Groenewold \\ Department of Economics, \\ University of Western Australia, \\ Nedlands, WA 6009 \\ Australia \\ Phone +61 (08) 93803345 \\ Fax: +61 (08) 93801016 \\ E-mail: nic.groenewold@uwa.edu.au
}

We are grateful to Patric Hendershott and participants at the 2003 Money, Macro and Finance Conference held at the University of Cambridge for their helpful comments on a previous draft of this paper. 


\title{
US SHARE PRICES AND REAL SUPPLY AND DEMAND SHOCKS
}

\begin{abstract}
Using theoretical foundations, VAR restrictions are imposed allowing demand and supply sources of output movement to be distinguished and the effects of their shocks on stock prices to be analysed. Stock prices are sensitive to all shocks although the influence from the real economy to the stock market is less important than shocks that are peculiar to the market itself. Decompositions using temporary/permanent and real economy/stock market distinctions suggest that the historical contribution of demand, supply and portfolio shocks to real stock price fluctuations changes over time - a feature that is particularly evident post mid-1990s.
\end{abstract}


INTRODUCTION

The interaction between the stock market and aggregate economic activity has been the subject of considerable interest in the past decade. The relationship has traditionally been one in which the economy affects the stock market, usually based on the common text-book model of share prices as the discounted present value of expected future dividends. In this framework share prices are influenced both by output (via profits and dividends) and interest rates (via the rate at which future dividends are discounted).

More recently, attention has also been focussed on effects in the opposite direction, that is from the stock market to the economy, no doubt influenced by the strong stock market performance in the 1990s and the sharp "corrections" in 2001 following the long bull market. The extant literature has identified two principal channels of influence, the first from stock prices to consumption via a wealth effect and the second from stock prices to investment via cost of capital and other influences. $^{1}$

The vector auto-regressive (VAR) model has been a popular one for the analysis of the intertemporal relationships between macro variables and stock prices; it requires little by way of prior theoretical structure and the tools for the estimation and analysis of the dynamic behaviour of such models are widely available. An early VAR analysis in this area is the one by Lee (1992) and more recent ones are by Cheung and $\mathrm{Ng}$ (1998) and Gjerde and Saettem (1999). One of the costs of the atheoretical nature of the VAR is that the shocks in the model are difficult to interpret in economic terms. Indeed, if we view the VAR as a reduced form of a structural

\footnotetext{
${ }^{1}$ See Mullins and Wadhwani (1989), Barro (1990), Morck, Schleifer and Vishny (1999), Blanchard, Rhee and Summers (1993), and Chirinko and Schaller (1996) on the investment effect and Romer (1990), Poterba and Samwick (1995), Parker (1999), Poterba (2000) and Starr-McCluer (2002) on the consumption effect.
} 
model, its error terms will be linear combinations of various structural errors. Thus, in a reduced-form VAR real output innovations will generally be combinations of supply and demand shocks that are not distinguished even though macro theory predicts that they may well have quite different effects on stock prices.

A recent strand of VAR models has imposed extra structure on the VAR in an attempt to overcome the difficulty in the interpretation of the shocks. Starting with Bernanke (1986), Sims (1986), Blanchard (1989a) and Blanchard and Quah (1989), methods were devised to restrict the generality of the VAR by imposing restrictions based on prior theorising, thus enabling the interpretation of the shocks in terms of the theoretical priors. Sims, Bernanke and Blanchard all used short-run restrictions while Blanchard and Quah based their restrictions on the long-run relations between the variables. Subsequent work such as that by Gali (1992) has combined these two types of restrictions.

While original applications of these structural VARs (SVARs) was in the area of macroeconomics (and this continues to be a focus - see, e.g., Rapach, 1998), in recent years applications have also been to financial economics. In a series of papers, Lee et al. have applied SVAR models to the analysis of stock markets. In Lee (1995), Lee (1998) and Chung and Lee (1998) the focus was on the decomposition of stock prices into temporary and permanent components using models including financial variables such as dividends, earnings and interest rates. In Hess and Lee (1999) the same technique was applied to address the puzzle that stock returns are generally found to be negatively related to inflation, a puzzle which is at least partially resolved by using the model to distinguish between demand and supply shocks. All of the Lee et al. papers use the Blanchard and Quah identification procedure based on long-run restrictions. 
Another series of papers by Gallagher and Taylor also focus largely on the decomposition of stock prices into temporary and permanent components using the Blanchard-Quah identification scheme although, in contrast to the Lee et al. papers, the identification proceeds using inflation rather than financial variables as the additional identifying variable. In Gallagher (1999) the Blanchard and Quah procedure is applied to a VAR in two variables (stock prices and inflation) to identify temporary and permanent components in stock prices for 16 European countries while in Gallagher and Taylor (2000) a similar technique is applied to US data, using nominal interest rates as the second identifying variable in the place of inflation and applying estimation techniques which are robust to the usual departures from iidnormality common in financial data. In Gallagher and Taylor (2002a) the focus is, like Hess and Lee (1999), on the stock-price-inflation puzzle which is analysed in a model containing only these two variables. In Gallagher and Taylor (2002b) the model is again a two-variable VAR in inflation and stock returns which is used to decompose stock prices into temporary and permanent parts using the Blanchard and Quah procedure. In the latter paper, however, the restrictions used for identification are based on a simple macroeconomic model which allows the distinction between demand- and supply-driven components of inflation.

In the present paper we pursue this distinction between demand and supply shocks but apply it to output, rather than to inflation, since our interest is in the relationship between output and stock prices and, in particular, between the demandand supply-driven components of output on the one hand and stock prices on the other. Moreover, we argue that the identification of demand and supply components proceeds more naturally in terms of output than inflation or interest rates. 
We therefore begin by developing a macro model of the Blanchard and Quah type extended to include stock prices and use it as the basis for the identification of demand and supply components of the output innovations in a framework which includes the unemployment rate, in addition to output and stock prices, as the additional identifying variable in the spirit of the original Blanchard and Quah scheme. Our approach has most in common with a recent paper by Rapach (2001) which extends his earlier work, Rapach (1998), but uses a more extensive model and a different identification scheme to the one we propose.

Our empirical model also allows for an analysis of the relative effects of stock market (portfolio) shocks on output, unemployment and the stock market itself and hence the importance of such shocks to the real economy. Further, in order to characterise the sources of stock price fluctuations over the sample period, we decompose stock prices over the sample period. Our model is sufficiently rich in structure to allow two interesting decompositions. The first uses a distinction between permanent and temporary components, which has been used previously in the literature but not based on our identifying scheme; and the second distinguishes between real economy and stock market components of stock price fluctuations which, as far as the authors are aware, has not been considered by the existing literature. The only temporary shock in our model is a demand one so that the temporary component of stock prices is that component which results from demanddriven output fluctuations with supply-based output fluctuations and stock market shocks both having permanent effects. The real/stock market decomposition separates demand and supply influences on the one hand from stock market shocks on the other. Utilising these decompositions provides an opportunity to analyse the changing characteristics of real stock price fluctuations. 
We find that the demand/supply/portfolio distinction is important in that, consistent with theoretical predictions, demand and supply shocks both have positive effects on real stock prices. While stock prices are sensitive to all shocks, the influence from the real economy to the stock market is less important than shocks that are peculiar to the market itself. Decompositions using temporary/permanent and real economy/stock market distinctions suggest that the historical contribution of demand, supply and portfolio shocks to real stock price fluctuations changes over time - a feature that is particularly evident post mid-1990s.

The structure of our paper is as follows. In section 2 we set out a simple macro model which we use to motivate our restrictions. In section 3 we set out the SVAR and explain the way in which we identify the demand and supply shocks and compute the decomposition of stock prices into demand and supply components. We go on in section 4 to a discussion of the data used, including tests of stationarity and cointegration before turning to a discussion of our results in section 5. Conclusions are presented in section 6 .

\section{THE THEORETICAL MODEL}

We begin with the model which Blanchard and Quah (1989) (henceforth BQ) use to motivate their empirical distinction between demand and supply shocks. The essential feature of the BQ model is that demand shocks (represented by innovations to the nominal money stock) have only temporary effects on real output, a feature which is achieved by imposing nominal inertia in a model with long-run monetary neutrality. While in the BQ model nominal inertia comes from a form of Taylor's (1980) staggered wage-setting scheme, we do not model wage-setting explicitly but capture the inertia by positing a Phillips-Curve-like relationship between the price level on the 
one hand and pressure in the labour market and the lagged price level on the other hand. Alternative formulations are in Hess and Lee (1999) and in Gallagher and Taylor (2002b) but both of these have some unusual features which we wish to avoid. $^{2}$

The core of the model is the following three equations - the first capturing aggregate demand, the second aggregate supply and the third the price equation:

$$
\begin{array}{ll}
y_{t}=m_{t}-p_{t}+\beta \theta_{t}, & \beta \geq 0 \\
y_{t}=n_{t}+\theta_{t} & \\
p_{t}=\alpha\left(n_{t}-n^{*}\right)+{ }_{t-1} p_{t}^{*}, & \alpha \geq 0
\end{array}
$$

All variables are in logs and $y$ represents real output, $m$ the nominal money supply, $p$ the price level, $n$ employment, $\theta$ productivity, $n^{*}$ the exogenous labour force, and ${ }_{t-1} p_{t}{ }^{*}$ the expectation of the current price level based on past information. We place few restrictions on the expected price level except to require that expectations are predetermined in the short run and realised in the long run. Thus rational expectations based on lagged information are consistent with this property as are adaptive expectations. The price equation has the property that in the long run when price expectations are realised, employment is at its full-employment level so that the unemployment rate is not affected by any shocks in the long run.

It will be noted that, in contrast to the specifications in the other papers cited above, our model is deterministic, although dynamic due to the presence of price expectations based on lagged information. We find a deterministic formulation more transparent than the more common stochastic form and nothing is lost in the simplification of the models. Thus, e.g., the BQ model may be solved in deterministic

\footnotetext{
2 The Hess and Lee (1999) model achieved nominal inertia by unaccountably including the lagged interest rate in their price equation while Gallagher and Taylor (2002b) include profits (a real flow variable) in the price equation with a unit coefficient, a feature which appears necessary to ensure that there are short-run effects of a monetary shock on the price level.
} 
form with $m$ the demand shock and $\theta$ the supply shock to obtain the result that the demand shock has only a temporary effect on output, the supply shock has both a long-run and a short-run effect on output and neither shock has a long-run effect on unemployment which are the only properties of the model used to constrain the VAR.

The BQ model does not include share prices and we add them in the manner of Hess and Lee (1999) and of Blanchard (1989b) by assuming real share prices to be dependent on real output via dividends and profits. We also follow Blanchard (1989b) in assuming a direct effect of share prices on real demand via either consumption or investment (see references in footnote 1 which have found empirical support for such a relationship). The model then becomes:

$$
\begin{array}{ll}
y_{t}=m_{t}-p_{t}+\beta \theta_{t}+\gamma\left(s_{t}-p_{t}\right), & \beta \geq 0, \gamma \geq 0 \\
y_{t}=n_{t}+\theta_{t}, & \\
p_{t}=\alpha\left(n_{t}-n^{*}\right)+{ }_{t-1} p_{t}^{*}, & \alpha \geq 0 \\
s_{t}=\phi y_{t}+p_{t}, & \phi>0
\end{array}
$$

where $s_{t}$ represents the log of (nominal) share prices. To these equations we add the definition of the unemployment rate, $u_{t}$ :

$$
u_{t}=n^{*}-n_{t}
$$

where the natural rate of unemployment has been normalised at zero. In the model we capture demand shocks through the money stock, $m_{t}$, and supply shocks through the productivity variable, $\theta_{t}$. We add a (real) stock market shock, $\mu_{t}$, to the stock price equation to capture real permanent shocks to stock prices which do not emanate from the real part of the economy. We can think of these shock as changes in preferences for shares or a change in risk aversion, provided the shock does not have a direct effect on the rest of the model. This is in contrast to, say, a real interest rate shock 
which will induce a change in the real price of shares for given $y$ but may also affect real demand through investment and/or consumption.

The final form of the model is then:

$$
\begin{array}{ll}
y_{t}=m_{t}-p_{t}+\beta \theta_{t}+\gamma\left(s_{t}-p_{t}\right), & \beta \geq 0, \gamma \geq 0 \\
y_{t}=n_{t}+\theta_{t} & \\
p_{t}=\alpha\left(n_{t}-n^{*}\right)+{ }_{t-1} p_{t}^{*}, & \alpha \geq 0 \\
s_{t}=\phi y_{t}+p_{t}+\mu_{t}, & \phi>0 \\
u_{t}=n^{*}-n_{t} &
\end{array}
$$

The current endogenous variables are $y_{t}, p_{t}, n_{t}, u_{t}$ and $s_{t}$ with $m_{t}, n^{*}, \mu_{t}$ and $\theta_{t}$ being exogenous and ${ }_{t-1} p_{t}{ }^{*}$ being predetermined in the short run. In the long run ${ }_{t-1} p_{t}{ }^{*}$ becomes endogenous and we assume expectations are realised so that ${ }_{t-1} p_{t}{ }^{*}=p_{t}$.

To draw out the implications needed to constrain the VAR we solve for the three variables of interest $(y, u$ and $s-p$, dropping time subscripts where this will not lead to confusion) in both the short-run and long-run versions in turn. In the short run: ${ }^{3}$

$y=[m+(\beta+\alpha) \theta+\mu \gamma] /|A|$

$u=-[m+(\beta+\gamma \phi-1) \theta+\mu \gamma] /|A|$

$s-p=(\phi m+\alpha \phi \theta+\alpha \mu+\mu) /|A|$

where $|A|$ is the Jacobian determinant for the system (1)-(5) and equals $1+\alpha-\phi \gamma$. Note that the term $\phi \gamma$ measures the effect of an increase in $y$ on aggregate demand (the right-hand side of (1)) via its effects on profits, dividends and hence share prices; so, e.g., a rise in output raises profits which raises dividends which raises share prices which, in turn, raises consumption and so aggregate demand and thus initiates a

\footnotetext{
${ }^{3}$ Note that we have simplified by setting $p^{*}$ and $n^{*}$ equal to zero since shocks to these variables are not of interest in the present analysis.
} 
second-round increase in output. We make the reasonable assumption that this second-round increase in output is less than the increase in $y$ which set it off, otherwise increases in output would set off explosive dynamics through the wealth channel which seems highly unlikely given the usual empirical magnitudes of these effects. $^{4}$ In that case $\phi \gamma$ is less than 1 so that $|A|$ is unambiguously positive and we can sign the effects of the three shocks on the three variables of interest. The shortrun multipliers and their signs are given in the upper panel of TABLE 1.

Consider the long-run effects next. The long-run version of the model is defined by a single additional condition: $p^{*}=p$. Using this in equation (3) results in the standard vertical long-run Phillips Curve condition that $n=n^{*}$ or $u=0$ which is the natural rate in our model. The solutions for the three endogenous variables of interest are:

$u=0$

$y=n^{*}+\theta$

$s-p=\phi \theta+\mu$

The long-run effects of the shocks are summarised in the lower panel of TABLE 1.

\footnotetext{
4 Thus even if a $10 \%$ increase in output also increased current and expected future profits and dividends by $10 \%$, left the discount rate unaltered so that share prices rose by $10 \%$, the wealth effect on consumption is likely to increase consumption and therefore aggregate demand by less that $2 \%$; see Bertaut (2002) for calculations of the size of this effect for a variety of countries under various assumptions.
} 
TABLE 1: SHORT-RUN AND LONG-RUN MULTIPLIERS

\begin{tabular}{|c|c|c|c|}
\hline \multirow{2}{*}{$\begin{array}{l}\text { Endogenous } \\
\text { variable }\end{array}$} & \multicolumn{3}{|l|}{ Shock } \\
\hline & $M$ & $\theta$ & $\mu$ \\
\hline \multicolumn{4}{|c|}{ Short-run effects } \\
\hline$y$ & $1 /|A|$ & $(\beta+\alpha) / A \mid$ & $\gamma / A \mid$ \\
\hline$u$ & $-1 /|A|$ & $-(\beta+\gamma \phi-1) / A \mid$ & $-\gamma /|A|$ \\
\hline$s-p$ & $\phi|| A \mid$ & $\phi(\alpha+\beta) / A \mid$ & $\alpha+1 / A \mid$ \\
\hline \multicolumn{4}{|c|}{ Long-run effects } \\
\hline$y$ & 0 & 1 & 0 \\
\hline$u$ & 0 & 0 & 0 \\
\hline$s-p$ & 0 & $\phi$ & 1 \\
\hline
\end{tabular}

The signs of the short-run effects are plausible and are all determinate except for the productivity effect on unemployment which is of ambiguous sign: a productivity shock increases output but not necessarily by enough to offset the laboursaving technology improvement. All three shocks increase output and real stock prices; a demand shock and a stock market shock unambiguously reduce unemployment but, as explained above, a productivity shock may increase or decrease unemployment depending on the strength of the output effect.

In its long-run form, the model has the desired qualities of long-run neutrality - the effect of a nominal demand shock is to leave real output and unemployment unaffected, to change the two nominal variables, $p$ and $s$ equi-proportionately, so that real stock prices are also unaffected by demand shocks. Moreover, the productivity shock has positive effects in the long run on both output and real stock prices while the stock market shock has a long-run effect only on stock prices themselves. 
We can use the model implications to identify the three shocks empirically as follows: the demand shock has a long-run effect on none of the three variables, the stock market shock has a long-run effect only on real stock prices and the supply shock has a long-run effect on both real stock prices and real output. The sign pattern of longrun effects may be represented as:

$$
\left[\begin{array}{l}
u \\
y \\
(s-p)
\end{array}\right]=\left[\begin{array}{lll}
0 & 0 & 0 \\
x & 0 & 0 \\
x & 0 & x
\end{array}\right]\left[\begin{array}{l}
\theta \\
m \\
\mu
\end{array}\right]
$$

where an " $x$ " indicates that there is a potential long-run effect and a " 0 " that there is no long-run effect. These can be used in the formal identification of the VAR as follows.

Note first that the pattern of the coefficient matrix in (6) implies that $u$ will be stationary and that $y$ and $(s-p)$ will be potentially non-stationary since none of the shocks has a permanent effect on $u$ but $\theta$ may have an effect on both $y$ and (s-p) in the long run and $\mu$ may have an effect on $(s-p)$ in the long run. We assume $y$ and (s-p) to be non-stationary and $u$ to be stationary in what follows although we will test this implication in the empirical section.

Consider the three-equation structural model written as a linear dynamic model in the vector of stationary endogenous variables $\boldsymbol{x}=(u, \Delta y, \Delta(s-p))^{\prime}$ :

$$
\boldsymbol{B}(0) \boldsymbol{x}_{t}=\boldsymbol{b}_{0}+\boldsymbol{B}(L) \boldsymbol{x}_{t-1}+\varepsilon_{t}
$$

where $L$ is the lag operator, $L^{j} \boldsymbol{x}_{t}=\boldsymbol{x}_{t-j}, \boldsymbol{B}(0)$ is a (3x3) matrix of coefficients of the current values of the endogenous variables with representative element $b_{i j}(0)$ and $\boldsymbol{b}_{0}$ and $\varepsilon$ are $(3 \times 1)$ vectors of intercepts and structural shocks (i.e., supply, demand and stock market shocks). $\boldsymbol{B}(L)$ is a matrix polynomial in the lag operator: 


$$
\boldsymbol{B}(L)=\boldsymbol{B}(1)+\boldsymbol{B}(2) L+\boldsymbol{B}(3) L^{2}+\boldsymbol{B}(4) L^{3}+\ldots+\boldsymbol{B}(p) L^{p-1}
$$

where each of the $\boldsymbol{B}(k)$ are $(3 \times 3)$ matrices of coefficients with representative element $b_{i j}(k)$.

An estimated form of (7) will be used to simulate the effects of shocks to the $\mathcal{E}_{i} \mathrm{~S}$ on the $x_{j} \mathrm{~s}$. However, (7) can not be estimated as it stands since it is not identified. Instead we estimate the reduced form VAR:

$$
\boldsymbol{x}_{t}=\boldsymbol{a}_{0}+\boldsymbol{A}(L) \boldsymbol{x}_{t-1}+\boldsymbol{e}_{t}
$$

which is related to (7) by $\boldsymbol{a}_{0}=\boldsymbol{B}(0)^{-1} \boldsymbol{b}_{0}, \boldsymbol{A}(L)=\boldsymbol{B}(0)^{-1} \boldsymbol{B}(L), \boldsymbol{e}_{t}=\boldsymbol{B}(0)^{-1} \varepsilon_{t}$. Hence, if we can identify the elements of $\boldsymbol{B}(0)$ we can estimate the reduced form VAR and compute numerical values for the elements of (7) which can, in turn, be used for the computation of a numerical version of the structural vector moving average (SVMA) form of the model:

$$
\boldsymbol{x}_{t}=\boldsymbol{c}_{0}+\boldsymbol{C}(L) \varepsilon_{t}
$$

where $\boldsymbol{C}(L)=(\boldsymbol{B}(0)-\boldsymbol{B}(L) L)^{-1}, \boldsymbol{c}_{0}=\boldsymbol{C}(L) \boldsymbol{b}_{0}$.

Thus to use the estimated reduced form to simulate the effects of shocks to the structural errors (the demand, supply and stock market shocks) we need to identify the nine elements of the $\boldsymbol{B}(0)$. This is achieved by the use of the following nine restrictions:

(i) the structural shocks are normalised to have unit variances (three restrictions)

(ii) the structural shocks are assumed to be uncorrelated (three restrictions), and

(iii) the long-run restrictions from the macro model are imposed:

(a) the demand shock has no long-run effect on real output, (b) the demand shock has no long-run effects on real stock prices, and 
(c) the stock market shock has no long-run effects on real output. ${ }^{5}$

We note that the empirical application is inevitably broader than the illustrative theoretical model in section II. Thus, e.g., the supply shock corresponds to productivity in the model but in the SVAR it captures any shock which has a permanent effect on real output and, similarly, the demand shock is a money supply shock in the theoretical model but in the SVAR it captures any shock which has only a temporary effect on real stock prices, real output and the unemployment rate.

\section{$4 \quad$ THE DATA}

We use quarterly US data for the period 1947:4 to 2002:4. The unemployment rate is measured by the civilian unemployment rate, output by real GDP and real stock returns by S\&P500 real stock returns (including dividends). The unemployment and GDP data are taken from FRED, the data base maintained by the Federal Reserve Bank of St Louis and real stock returns from Ibbotson Associates. Real stock returns and the growth rate of real output are computed as log first-differences. Summary statistics are reported in TABLE 2. All three variables show significant departures from normality, particularly the real return to shares which exhibit significant negative skewness and excess kurtosis.

\footnotetext{
${ }^{5}$ Note that the model also implies a zero long-run effect of all three shocks on the unemployment rate. This is imposed on the model by specifying a stationary model with the unemployment rate in level form while real output and real stock prices are entered in first-difference form to allow for the possibility of long-run effects of productivity shocks on output and of productivity and stock market shocks on real stock prices.
} 
TABLE 2: SUMMARY STATISTICS

\begin{tabular}{|l|c|c|c|c|c|}
\hline Variable & Mean (\%) & SD (\%) & Skewness & Kurtosis & JB (prob) \\
\hline $\mathrm{U}$ & 5.6350 & 1.5560 & 3.0988 & 0.5778 & 0.0084 \\
\hline $\log (\mathrm{y})-\log \left(\mathrm{y}_{-1}\right)$ & 0.8372 & 1.0374 & -0.5322 & 3.4469 & 0.0039 \\
\hline $\log (\mathrm{s}-\mathrm{p})-\log \left((\mathrm{s}-\mathrm{p})_{-1}\right)$ & 1.8300 & 7.9722 & -5.5937 & 5.9884 & 0.0000 \\
\hline
\end{tabular}

Note: the skewness and (excess-) kurtosis statistics are standard-normally distributed under the null of normality. JB is the Jarque-Bera statistic for normality.

The model set out in the previous two sections requires that the unemployment rate be stationary and that real output and real stock prices be I(1). The model is also specified on the assumption that if, $y$ and $(s-p)$ are indeed I(1), they are not cointegrated. We therefore proceed to tests of stationarity and cointegration. Tests for stationarity are reported in TABLE 3 . Both $(\log )$ output and real stock prices are clearly I(1), irrespective of lag length and the presence or absence of a trend term in the Dickey-Fuller equation. The results for the unemployment rate are not quite so clear-cut: the test outcome is dependent on lag length whether a trend term is present or not. We therefore examined the Dickey-Fuller equation: in the equation without trend at least one lag is necessary to remove autocorrelation which is absent at the $5 \%$ level with one lag and at the $10 \%$ level with two lags. The results for $\operatorname{ADF}(1)$ and $\operatorname{ADF}(2)$ are therefore appropriate. If a trend is included in the equation it is not significant in any equations estimated; besides, with a trend the $\operatorname{ADF}(1)$ and $\operatorname{ADF}(2)$ statistics are again appropriate on the basis of the autocorrelation criterion. In all appropriate cases we can reject the null of non-stationarity and conclude that $u$ is $\mathrm{I}(0)$. 
TABLE 3: STATIONARITY

\begin{tabular}{|l|r|r|r|r|r|}
\hline \multicolumn{1}{|c|}{ Test } & $\mathrm{u}$ & $\log (\mathrm{y})$ & \multicolumn{1}{l|}{$\log (\mathrm{s}-\mathrm{p})$} & $\mathrm{d} \log (\mathrm{y})$ & $\mathrm{d} \log (\mathrm{s}-\mathrm{p})$ \\
\hline \multicolumn{1}{|l|}{ (a) Intercept, no trend } \\
\hline ADF(0) & -2.2330 & -1.5065 & -1.783 & -10.3769 & -12.6994 \\
\hline ADF(1) & -3.6540 & -1.1815 & -1.7429 & -7.8234 & -9.7638 \\
\hline ADF(2) & -3.6650 & -1.1345 & -1.7328 & -7.5615 & -7.675 \\
\hline ADF(3) & -3.1717 & -1.2062 & -1.7286 & -7.5233 & -6.5626 \\
\hline ADF(4) & -2.7912 & -1.3094 & -1.7243 & -7.3788 & -5.8278 \\
\hline (b) Intercept and trend & -2.2207 & -2.013 & -2.0594 & -10.4608 & -12.7424 \\
\hline ADF(0) & -3.7771 & -2.7901 & -2.1998 & -7.912 & -9.8174 \\
\hline ADF(1) & -3.8019 & -3.0593 & -2.1379 & -7.6677 & -7.7324 \\
\hline ADF(2) & -3.2762 & -2.8174 & -2.1809 & -7.6565 & -6.627 \\
\hline ADF(3) & & & & & \\
\hline ADF(4) & -2.8532 & -2.5516 & -2.2137 & -7.5407 & -5.8939 \\
\hline
\end{tabular}

Note: The $5 \%$ critical value for tests without a trend is -2.8751 ; for tests including a trend it is -3.4319 .

Before concluding that our model specification is correct, we test for cointegration between $\log (y)$ and $\log (s-p)$. The results of both the Engle-Granger and Johansen tests are reported in TABLE 4. It is clear from all the tests that the two variables are not cointegrated. The statistical nature of the variables therefore supports our specification of the VAR as one in the level of the unemployment rate and the log first-differences of real output and real stock prices. We now turn to the estimation and simulation of this model. 
TABLE 4: COINTEGRATION

\begin{tabular}{|c|c|c|c|c|}
\hline \multicolumn{5}{|c|}{ (a) Engle-Granger } \\
\hline Test & \multicolumn{2}{|c|}{ Without trend } & \multicolumn{2}{|c|}{ With trend } \\
\hline Lag $=0$ & \multicolumn{2}{|c|}{-1.4551} & \multicolumn{2}{|c|}{-2.3831} \\
\hline $\operatorname{Lag}=1$ & \multicolumn{2}{|c|}{-1.5804} & \multicolumn{2}{|c|}{-2.987} \\
\hline $\operatorname{Lag}=2$ & \multicolumn{2}{|c|}{-1.4484} & \multicolumn{2}{|c|}{-3.2285} \\
\hline Lag $=3$ & \multicolumn{2}{|c|}{-1.475} & \multicolumn{2}{|c|}{-3.0417} \\
\hline Lag $=4$ & \multicolumn{2}{|c|}{-1.473} & \multicolumn{2}{|c|}{-2.772} \\
\hline \multicolumn{5}{|l|}{ (b) Johansen } \\
\hline & \multicolumn{2}{|c|}{ Without trend } & \multicolumn{2}{|c|}{ With trend } \\
\hline Test & Statistic & $5 \%$ c. v. & Statistic & $5 \%$ c.v. \\
\hline Trace & 5.9552 & 17.8600 & 11.8875 & 23.8300 \\
\hline $\mathrm{ME}$ & 4.2780 & 14.8800 & 9.9265 & 18.3300 \\
\hline
\end{tabular}

Notes: the 5\% critical value for the Engle-Granger test without trend is -3.3660 and for the case with a trend it is -3.8257 . "Trace" is the test statistic for Johansen's trace test and "ME" is that for his maximum eigenvalue test. In each case the null hypothesis is that the variables are not cointegrated. The Johansen tests all include an intercept.

\section{$5 \quad$ RESULTS}

We begin by reporting standard statistics used in the choice of lag length in TABLE 5. 
TABLE 5: VAR LAG LENGTH

\begin{tabular}{|c|c|c|c|}
\hline Lag & AIC & SC & HQ \\
\hline 0 & -14.09201 & -14.04451 & -14.07282 \\
\hline 1 & -17.49678 & -17.30679 & -17.41999 \\
\hline 2 & $-17.90829 *$ & $-17.57579 *$ & $-17.77390^{*}$ \\
\hline 3 & -17.86996 & -17.39497 & -17.67798 \\
\hline 4 & -17.82279 & -17.20530 & -17.57321 \\
\hline 5 & -17.80165 & -17.04167 & -17.49448 \\
\hline 6 & -17.84083 & -16.93835 & -17.47607 \\
\hline 7 & -17.78622 & -16.74124 & -17.36386 \\
\hline
\end{tabular}

Note: an * indicates the optimum lag length according to each criterion.

The results indicate clearly that two lags is optimum. We therefore proceed with the estimation of an unrestricted VAR of order 2.

The estimated VAR is reported in TABLE 6. The unemployment equation has a high value of $\mathrm{R}^{2}$ and all but one coefficient is significant. Both real output growth and stock returns have a lagged negative effect on unemployment as expected. The explanatory power of the output growth equation is less strong although still high given that it is specified in terms of first differences. It is clear that there is a robust and positive feedback from real share returns to output growth. Not unexpectedly, the explanatory power of the real stock return equation is low reflecting the inability to predict returns as hypothesised by the efficient markets hypothesis (EMH). 
TABLE 6: UNRESTRICTED VAR

\begin{tabular}{|c|c|c|c|}
\hline Variable & u equation & dlog(y) equation & dlog(s-p) equation \\
\hline \multirow[t]{2}{*}{$\mathrm{u}_{-1}$} & 1.1416 & -1.3422 & 2.0078 \\
\hline & {$[15.94]$} & {$[8.35]$} & {$[1.21]$} \\
\hline \multirow[t]{2}{*}{$\mathrm{u}_{-2}$} & -0.2049 & 1.3755 & -1.3781 \\
\hline & [2.94] & {$[8.80]$} & {$[0.85]$} \\
\hline \multirow[t]{2}{*}{$\mathrm{Dlog}(\mathrm{y})_{-1}$} & -0.1412 & -0.0074 & 0.5444 \\
\hline & {$[5.07]$} & {$[0.12]$} & {$[0.84]$} \\
\hline \multirow[t]{2}{*}{$\operatorname{Dlog}(y)_{-2}$} & -0.0261 & -0.0984 & -0.4153 \\
\hline & {$[0.96]$} & {$[1.62]$} & {$[0.66]$} \\
\hline \multirow[t]{2}{*}{$\operatorname{dlog}(s-p)_{-1}$} & -0.0120 & 0.0193 & 0.0916 \\
\hline & {$[4.07]$} & [2.91] & {$[1.34]$} \\
\hline \multirow[t]{2}{*}{$\mathrm{d} \log (s-p)_{-2}$} & -0.0110 & 0.0225 & -0.0422 \\
\hline & [3.51] & [3.19] & {$[0.58]$} \\
\hline \multirow[t]{2}{*}{ const } & 0.0055 & 0.0066 & -0.0193 \\
\hline & {$[5.33]$} & {$[2.86]$} & {$[0.81]$} \\
\hline $\mathrm{R}^{2}$ & 0.9523 & 0.4488 & 0.0399 \\
\hline Autocorrelation & 0.015 & 0.538 & 0.443 \\
\hline Functional Form & 0.783 & 0.029 & 0.003 \\
\hline Normality & 0.000 & 0.007 & 0.000 \\
\hline Heteroskedasticity & 0.176 & 0.997 & 0.445 \\
\hline
\end{tabular}

Notes: Figures in brackets below estimated coefficients are t-ratios; figures for autocorrelation, functional form, normality and heteroskedasticity are prob values; the autocorrelation test is a Lagrange multiplier test of first- to fourth-order autocorrelation, the test for functional form is Ramsey's RESET test, the test for normality is the Jarque-Bera test and the test for heteroskedasticity is based on the regression of squared residuals on squared predicted values. 
The diagnostics show that none of the equations is without weaknesses. The problem of most concern is that of residual autocorrelation in the unemployment equation. An inspection of the autocorrelation function for the residuals shows that there is no autocorrelation at lags 1,2 and 3 but a strong spike only at lag 4 suggesting the possibility of seasonality in the unemployment rate. However, the unemployment data are seasonally adjusted and a regression of $u$ on a constant and seasonal dummy variables indicates no significant seasonal pattern. Moreover, adding seasonal dummies to the VAR does not remove the evidence of autocorrelation. Finally, increasing lag length also has no beneficial effect on this problem. We therefore proceed with the model as specified despite the diagnostics and later report extensive experimentation with alternative specifications of the model. To anticipate our conclusions there, we find that the general nature of the dynamic response of the model to structural shocks is not affected by changes in specification including the addition of more lags, a trend and seasonal dummy variables.

We next report the estimated long-run response matrix, i.e. the coefficient matrix on the right-hand side of equation (6) above. The estimated long-run responses not constrained to zero are reported in TABLE 7.

TABLE 7: LONG-RUN RESPONSES

\begin{tabular}{|c|c|c|}
\hline Response & Coefficient & t-ratio \\
\hline Supply shock on $y$ & 0.0062 & 20.88 \\
\hline Supply shock on $(s-p)$ & 0.0150 & 3.28 \\
\hline Stock market shock on $(s-p)$ & 0.0665 & 20.98 \\
\hline
\end{tabular}


Clearly, each of the effects is significant with a sign consistent with the predictions of the model set out TABLE 1: supply shocks have positive effects on both real output and real stock prices and the stock market shock has a positive effect on stock prices.

We now turn to an analysis of the dynamic implications of the model by examining the impulse response functions (IRFs) which are pictured in FIGURE 1. 

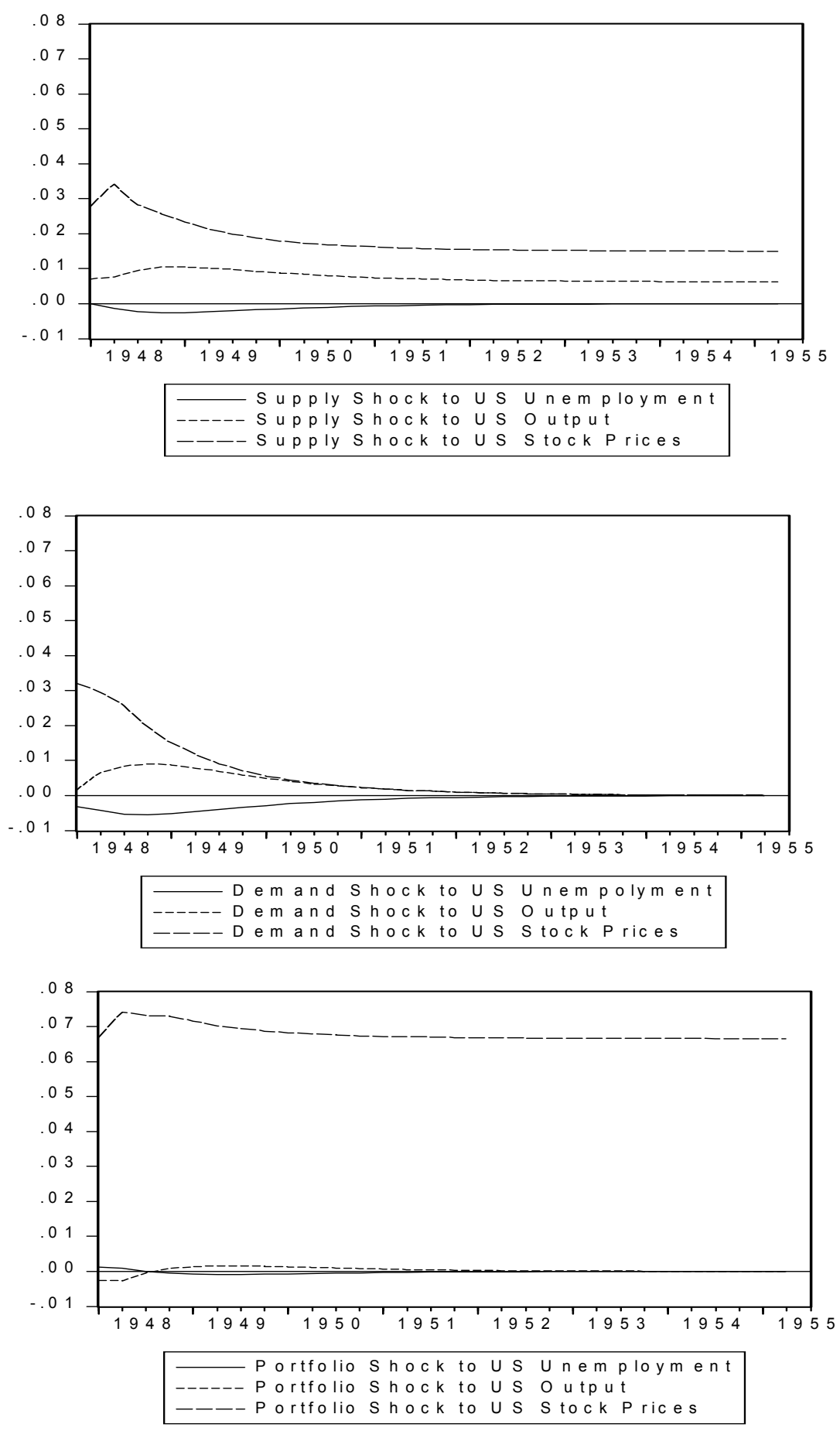

FIGURE 1: IMPULSE RESPONSE FUNCTIONS

The IRFs show the effects on the levels of the three variables of each of the structural shocks in turn. The first graph in FIGURE 1 shows the effects on all three 
variables of a supply shock; the initial effect on real output and real stock prices is positive and there is a negligible initial effect in unemployment. Over time the effects on output and real stock prices rise and then fall to a positive steady-state level. These short- and long-run effects are all consistent with the predictions of the theoretical model set out in section 2. The dynamics of output are reflected in the behaviour of the unemployment rate: initially the conflicting effects described in section 2 (expanding output and labour-saving technological progress) offset each other but as output rises further the employment expansion effect comes to dominate the labour-saving effect and unemployment falls in the subsequent three quarters after which it rises to its original long-run level.

The second graph shows the effects of a demand shock which reduces unemployment and increases output and stock prices in the short run but has no longrun effects on any of the three variables. Again, both temporary and permanent effects are consistent with the model predictions as set out in TABLE 1.

The third graph in FIGURE 1 shows the effects of a shock to the stock market (portfolio shock) which, not surprisingly, has a large and permanent positive effect on real stock prices. Hence the effect of portfolio shocks is almost entirely felt on the stock market itself with a negligible effect on the real economy.

It is interesting to note that the nature of the effects on stock prices support the results of the earlier work discussed above although we use quite different theoretical and empirical models and identification assumptions. Thus, e.g., Hess and Lee (1999) focussed on the relationship between stock prices and inflation and, in a model containing only these two variables, defined demand shocks as those which have only a temporary effect on stock prices while supply effects have permanent effects on both variables. Despite our model and our identifying assumptions being quite 
different, our results that both demand and supply shocks have positive effects on stock prices but that supply shocks have larger effects are parallel to those of Hess and Lee for their post-war US sample. Similarly, Rapach (2001) uses a four-variable model including interest rates and prices but excluding the unemployment rate and identifies demand (money-supply) shocks as having permanent effects only on prices while supply effects have long-term effects on all four variables. He too finds that demand and supply shocks raise stock prices but that the supply effect is larger and, of course, longer-lasting. Thus the broad nature of these results seems to be robust with respect to model form and identifying assumptions.

Overall, the graphs in FIGURE 1 suggest that real stock prices are moved mostly by stock-market specific shocks and less, but about equally, by demand and supply shocks. We now proceed to assess this by computing an historical decomposition of real stock prices into the accumulation of the various shocks.

FIGURE 2 shows the decomposition of accumulated demeaned real stock returns into three components: accumulated demand shocks, supply shocks and stock market shocks. 

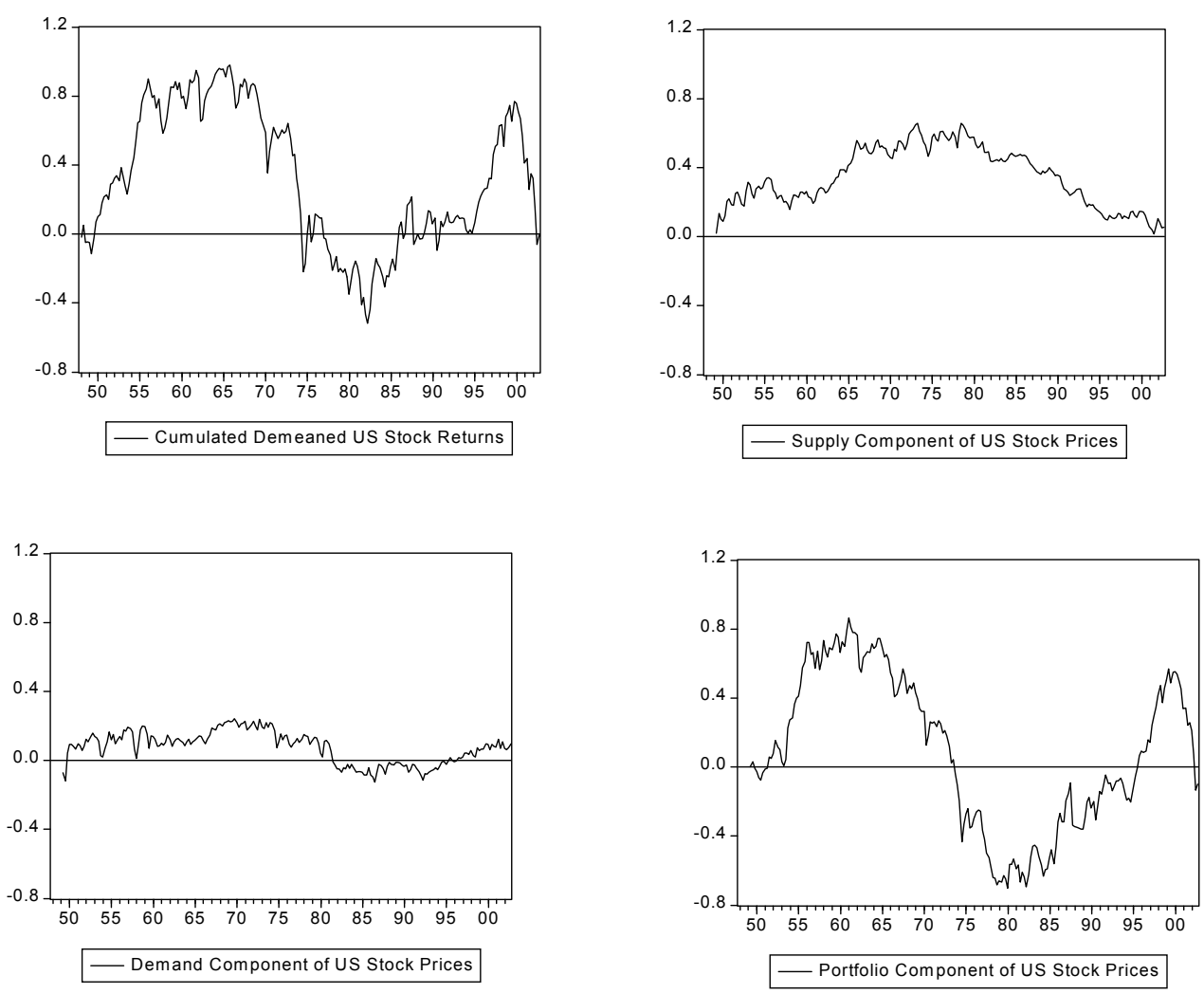

FIGURE 2: DECOMPOSITION OF REAL STOCK PRICES

It is clear from the first graph in FIGURE 2 that real US stock prices exhibit strong long-term cyclical behaviour and, interestingly, as the fourth graph in FIGURE 2 demonstrates, most of the cyclical shape has been driven by stock-market specific effects - although this does not imply that the stock market is relatively divorced from the goings-on in the real economy. Supply shocks, in particular, have added considerably to stock price movements especially in the 1970s and 1980s. While it is inappropriate to identify the supply component with the effects of productivity changes (as discussed in section 2) and without wanting to make too much of it, it is interesting nevertheless to note that there was a sharp negative change in the supply component in 1973 coinciding with the first oil-price shock and that the beginning of the secular decline in the supply component dates from the second oil-price shock in the late 1970s. In contrast to the effect of supply shocks, the influence of demand 
shocks on real stock prices appears to have been relatively unimportant at least until the latter part of the sample period.

We can investigate this further by using the supply, demand and portfolio components to decompose real stock prices in order to consider the influence of these components at different periods in time. We decompose real stock prices in two different ways. In the first we distinguish between temporary and permanent components, a decomposition which has been used before in the literature but has not been effected on the basis of an identification scheme such as we use based on output and unemployment. Thus, e.g., Lee (1995), Lee (1998) and Chung and Lee (1998) effect a decomposition based on financial identifying variables while Gallagher and Taylor $(2000,2002 b)$ use inflation to identify temporary and permanent components. We allocate only accumulated demand shocks into the temporary component since demand shocks are the only ones in our model which have a temporary effect and the accumulated effects of supply and portfolio shocks into the permanent component since both of these shocks have potentially permanent effects on real stock prices.

In the second decomposition, we distinguish between real economy (or fundamental) and financial components where the real economy component combines the accumulated effects of demand and supply shocks while the financial component is comprised of the accumulated effects of the portfolio shock.

Utilising such decompositions we can also compare the time paths of the relative effects of the portfolio and supply elements of the permanent component of stock prices, and the relative effects of the demand and supply elements on the real economy component of stock prices over the sample period. Such an analysis will provide information on the changing characteristics of real stock price fluctuations. 
The results of these decomposition exercises are pictured in FIGURE 3 through FIGURE 6.

FIGURE 3 shows the permanent (supply plus portfolio) and temporary (demand) components of real stock prices. ${ }^{6}$

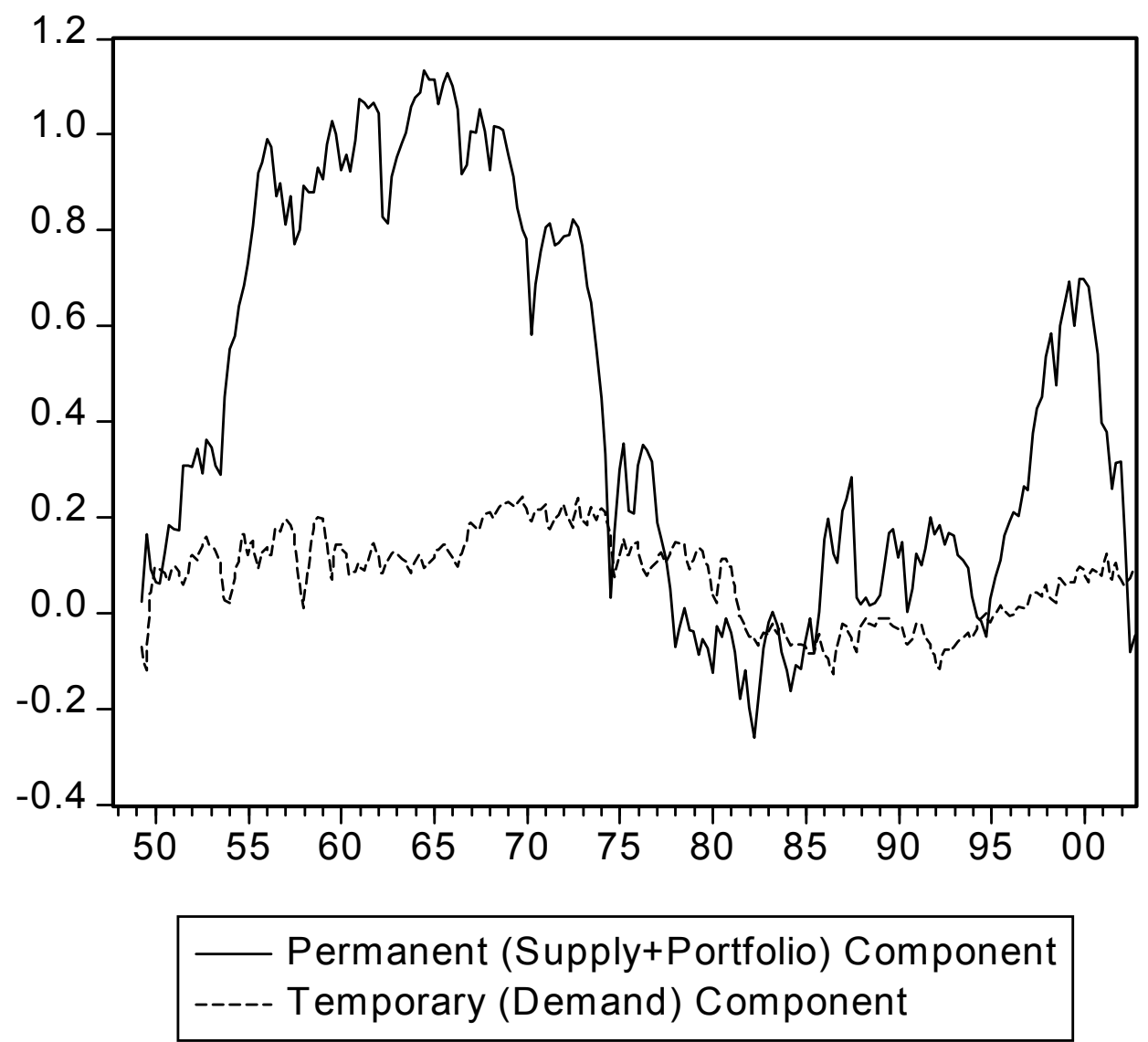

\section{FIGURE 3: PERMANENT AND TEMPORARY COMPONENTS OF US REAL STOCK PRICES.}

It is clear that over the period from the mid-1950s through to the early-mid 1970s, the permanent component dominated stock price fluctuations, with another period of domination being through the mid-late 1990s. The demand component however, was relatively more influential in the late 1970s through the early 1980s,

\footnotetext{
${ }^{6}$ The part of stock prices due to a constant has been excluded from the analysis in order to isolate the impact of supply, demand and portfolio components.
} 
and its influence would appear to be increasing in the latter part of the sample period. Overall, we find more variability in the permanent component of US stock prices than in the temporary component and while FIGURE 2 above suggests that the variability of the permanent component is dominated by stock market sentiment, it is not clear the extent to which this changes over time.

In order to characterise the time path of the relative effects of supply and market sentiment components of stock prices, in FIGURE 4 we show the permanent (supply plus portfolio) component alongside the portfolio component.

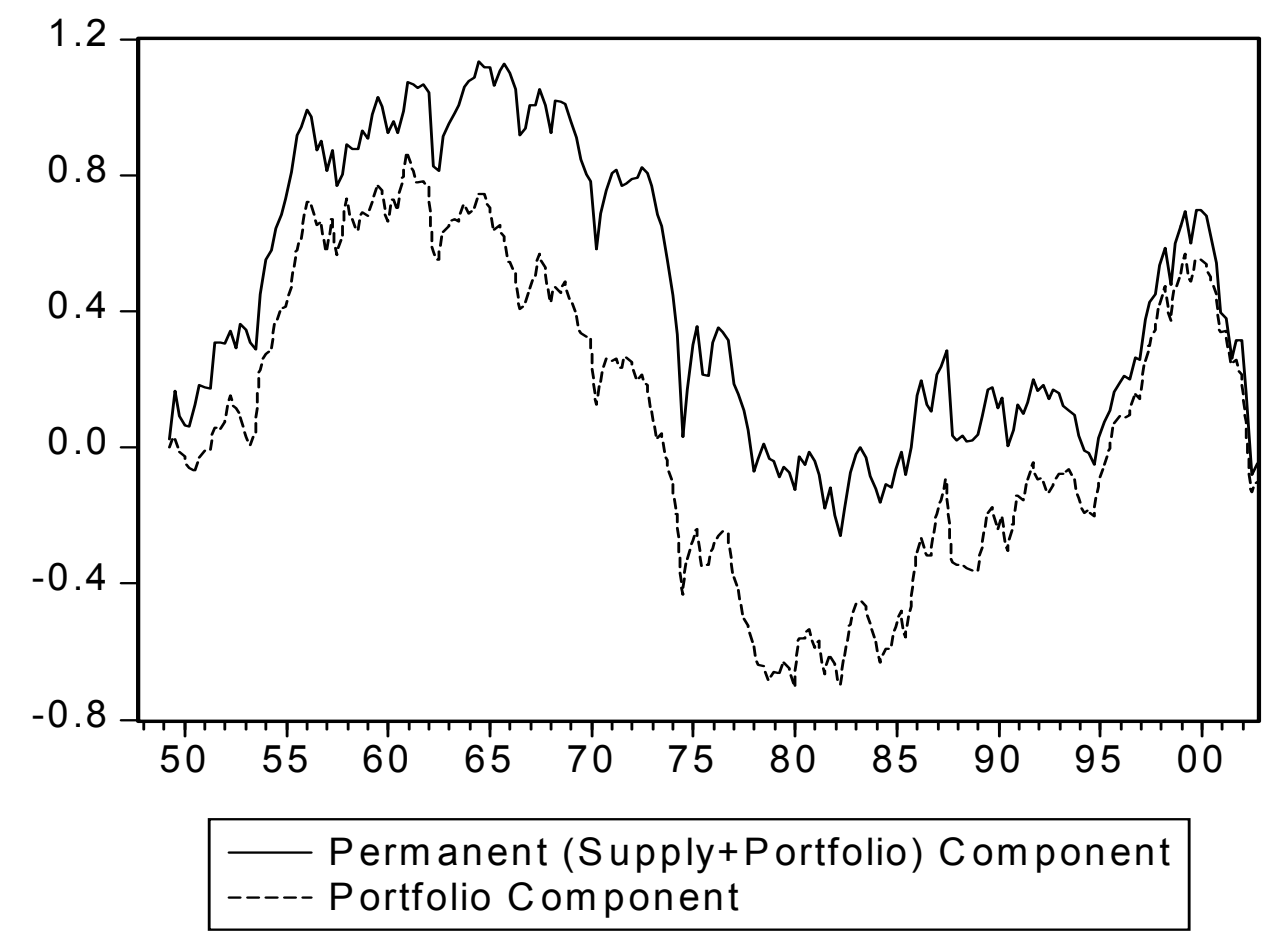

FIGURE 4: PERMANENT AND STOCK MARKET COMPONENTS OF US REAL STOCK PRICES.

FIGURE 4 shows that the two series display a similar cyclical pattern and that while the permanent component of real stock prices is dominated by portfolio shocks, the relative importance of supply and portfolio effects on the permanent component has not been constant over time. In particular, since the mid 1990s, the plot indicates 
that the supply element of the permanent component is very small indeed and has been decreasing in influence since the mid-1980s.

FIGURE 5 shows the real economy (supply plus demand) components of real stock prices alongside the portfolio or stock market component.
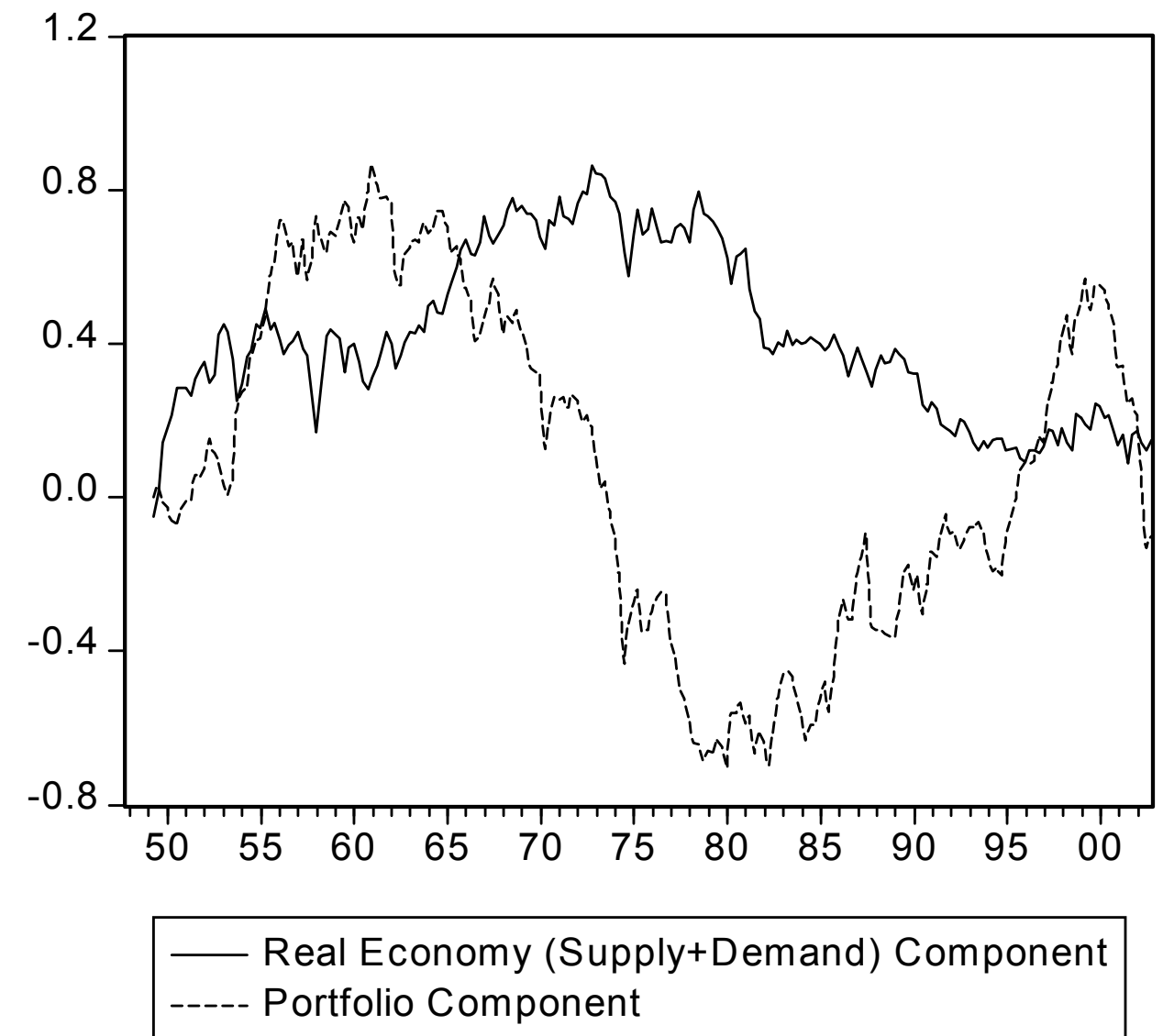

FIGURE 5: REAL ECONOMY AND STOCK MARKET COMPONENTS OF US REAL STOCK PRICES.

The plot shows that real economy shocks had a reinforcing effect during the expansion of 1950-70 and that the declining stock market sentiment during the 1970s was at importantly offset by a strong positive influence from the real economy. After 1980, however, the strong recovery in stock market sentiment was generally offset by the poor performance of the real economy. It is interesting that the stock market 
boom of the second part of the 1990s was largely based on stock market sentiment and happened despite a weak economy.

FIGURE 6, which plots the real economy (supply plus demand) and temporary (demand) components of stock prices, also shows changes in the relative influences of the supply and demand components on real stock prices.

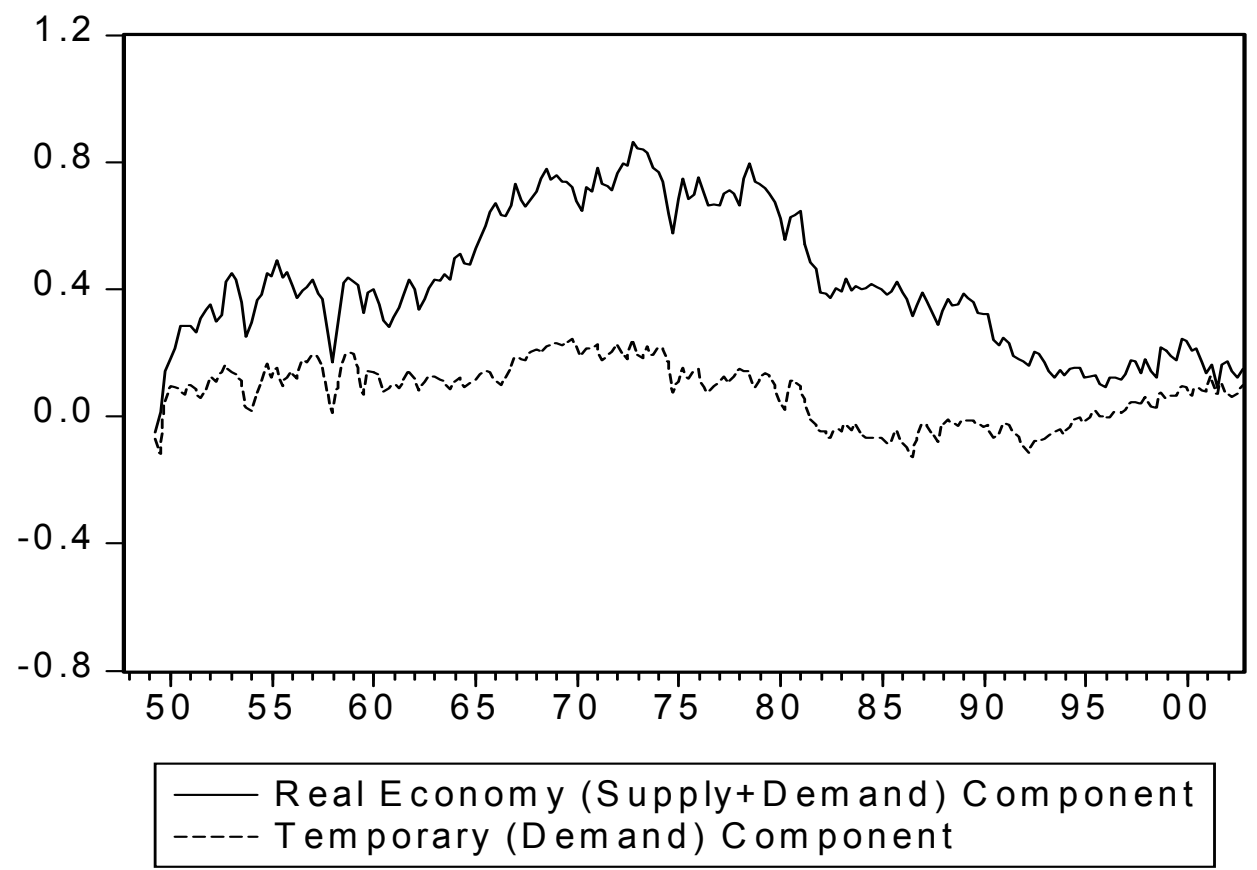

\section{FIGURE 6: REAL ECONOMY AND TEMPORARY COMPONENTS OF US REAL STOCK PRICES.}

Interestingly, the early-mid 1990s again appears to signal a change in stock price sensitivity to its components. In particular, from the early part of that decade we see an increasing role in the demand element of the real economy component of real stock prices with a decline in the influence of supply shocks.

\section{$6 \quad$ CONCLUSIONS}

In this paper we have set out a small theoretical macro model of the relationship between stock prices and output and used it to restrict a vector- 
autoregressive model in the unemployment rate, real output and real stock prices, which we estimated using quarterly US data for the period 1947-2002. We identified three different structural shocks: a supply shock, a demand shock and a stock market or portfolio shock. The supply shock was allowed to have permanent effects on output and stock prices but not on the unemployment rate, the demand shock was identified as having only temporary effects on all our three variables and the stock market shock had long-run effects on real stock prices but only short-run effects on real output and the unemployment rate.

We simulated the model and found that stock prices are sensitive to all three shocks including those emanating from the real economy, although the influence from the real economy to the stock market is less important than shocks which are peculiar to the market itself.

We also used the estimated model to decompose real stock prices in two ways. The first used a common distinction between temporary and permanent effects while the second decomposed real stock price movements into those emanating from the market itself and those driven by developments in the real economy. Utilising such decompositions we compared the time paths of the relative effects of the portfolio and supply elements of the permanent component of stock prices, and the relative effects of the demand and supply elements on the real economy component of stock prices over the sample period.

Overall, we found more variability in the permanent component of real US stock prices and that the influence of the elements of the permanent component (supply-driven output fluctuations and stock market sentiment-driven fluctuations) on these prices was not constant over time. The evidence reported suggests that while the effects of stock market sentiment has, over the sample, had a dominant role to play in 
the permanent component, since the mid-1990s the sensitivity of real stock prices to supply fluctuations has been very small indeed with almost all the variability of the permanent component being due to stock market sentiment. We also showed that stock market sentiment has been at odds with the performance of the real economy over substantial periods of time, and that the influence of supply and demand-driven output fluctuations on stock prices also changes in time. In particular the evidence suggests that since the mid-1990s, the sensitivity of real stock prices to supply-driven output fluctuations has waned while real stock price sensitivity to demand-driven output fluctuations has increased. Such observations suggest that stock price sensitivity to the real economy and financial influences not only changes over time but that price behaviour pre and post the early-mid 1990s in particular differs - a feature which has implications for policy and for empirical modelling. 


\section{REFERENCES}

Barro, R. J. (1990). 'The Stock Market and Investment', Review of Financial Studies Vol. 3, pp.115-131.

Bernanke, B. (1986). 'Alternative Explanations of the Money-Income Correlation', Carnegie-Rochester Conference Series on Public Policy, Vol. 25, pp. 49100.

Bertaut, C. C. (2002). 'Equity Prices, Household Wealth, and Consumption Growth in Foreign Industrial Countries: Wealth Effects in the 1990s', International Finance Discussion Papers No. 724, Board of Governors of the Federal Reserve System.

Blanchard, O. J. (1989a). 'A Traditional Interpretation of Macroeconomic Fluctuations', American Economic Review, Vol. 79, pp. 1146-1164.

Blanchard, O. J. (1989b). 'Output, the Stock Market and Interest Rates', American Economic Review, Vol. 71, pp.132-143.

Blanchard, O. J. and D. Quah (1989). 'The Dynamic Effects of Demand and Supply Disturbances', American Economic Review, Vol. 79, pp. 655-673.

Blanchard, O. J., C. Rhee and L. Summers (1993). 'The Stock Market, Profit and Investment', Quarterly Journal of Economics, Vol. 108, pp. 115-136.

Cheung, Y.-W. and L. K. Ng (1998). 'International Evidence on the Stock Market and Aggregate Economic Activity', Journal of Empirical Finance, Vol. 5, pp. 281-296.

Chirinko, R. S. and H. Schaller (1996). 'Bubbles, Fundamentals and Investment: A Multiple Equation Testing Strategy', Journal of Monetary Economics, Vol. 38, pp. 47-76.

Chung, H. and B-S. Lee (1998). 'Fundamental and Nonfundamental Components in Stock Prices of Pacific-Rim Countries', Pacific-Basin Journal of Finance Vol. 6, pp. 321-346.

Gali, J. (1992). 'How Well Does the IS-LM Model Fit the Postwar US Data?', Quarterly Journal of Economics, Vol. 107, pp. 709-738.

Gallagher, L. (1999). 'A Multi-Country Analysis of the Temporary and Permanent Components of Stock Prices', Applied Financial Economics, Vol. 9, pp.129142.

Gallagher, L. and M. P. Taylor (2000). 'Measuring the Temporary Component of Stock Price: Robust Multivariate Analysis', Economics Letters, Vol. 67, pp. 193-200.

Gallagher, L. and M. P. Taylor (2002a), "The Stock Return-Inflation Puzzle Revisited", Economics Letters, 75, pp. 147-156.

Gallagher, L. and M. P. Taylor (2002b). 'Permanent and Temporary Components of Stock Prices: Evidence from Assessing Macroeconomic Shocks', Southern Economic Journal, Vol. 69, pp. 345-362.

Gjerde, O. and F. Saettem (1999), 'Causal Relations among Stock Returns and Macroeconomic Variables in a Small, Open Economy', Journal of International Financial Markets, Institutions and Money, Vol. 9, pp. 61-47.

Hess, P. J. and B-S. Lee (1999), 'Stock Returns and Inflation with Supply and Demand Disturbances', The Review of Financial Studies Vol. 12, pp. 12031218.

Lee, B-S. (1992). 'Causal Relations among Stock Returns, Interest Rates, Real Activity and Inflation', Journal of Finance, Vol. 47, pp.1591-1603. 
Lee, B-S. (1995). 'The Response of Stock Prices to Permanent and Temporary Dividend Shocks', Journal of Financial and Quantitative Analysis, Vol. 30, pp. 1-22.

Lee, B-S. (1998). 'Permanent, Temporary and Non-Fundamental Components of Stock Prices', Journal of Financial and Quantitative Analysis, Vol. 33, pp. 132.

Morck, R., A. Schleifer and R. W. Vishny (1990). 'The Stock Market and Investment: Is the Market a Sideshow?', Brookings Papers on Economic Activity, Vol. 2, pp. 157-215.

Mullins, M., and S.B Wadhwani (1989). 'The Effect of the Stock Market on Investment: A Comparative Study', European Economic Review, Vol. 33, pp. 939-961.

Parker, J. A. (1999). 'Spendthrift in America? On Two Decades of Decline in the U.S. Saving Rate', NBER Macroeconomics Annual, pp. 317-370.

Poterba, J. M. (2000). 'Stock Market Wealth and Consumption', Journal of Economic Perspectives, Vol. 14, pp. 99-118.

Poterba, J. and A. Samwick (1995). 'Stock Ownership Patterns, Stock Market Fluctuations and Consumption', Brookings Papers in Economic Activity, No.2, pp. 295-372.

Rapach, D. E. (1998). 'Macro Shocks and Fluctuations', Journal of Economics and Business, Vol. 50, pp. 23-38.

Rapach, D. E. (2001). 'Macro Shocks and Real Stock Prices', Journal of Economics and Business, Vol. 53, pp.5-26.

Romer, C. D. (1990). 'The Great Crash and the Onset of the Great Depression', Quarterly Journal of Economics, Vol. 105, pp. 597-624.

Starr-McCluer, M. (2002). 'Stock Market Wealth and Consumer Spending', Economic Inquiry, Vol. 40, pp. 69-79.

Sims, C.A. (1986). 'Are Forecasting Models Usable for Policy Analysis?', Federal Reserve Bank of Minneapolis Quarterly Review, pp.3-16.

Taylor, J. B. (1980). 'Aggregate Dynamics and Staggered Contracts', Journal of Political Economy, Vol. 88, pp. 1-24 